\title{
The plasmid-located haloalkane dehalogenase gene from Rhodococcus rhodochrous NCIMB 13064
}

\author{
Anna N. Kulakova, Michael J. Larkin and Leonid A. Kulakov \\ Author for correspondence: Leonid A. Kulakov (Questor Centre). Tel: +44 1232335577. \\ Fax: +44 1232 661462. e-mail: 1.kulakov@queens-belfast.ac.uk
}

The Questor Centre, David Keir Building, The Queen's University of Belfast, Belfast BT9 5AG, UK and School of Biology and Biochemistry, Medical Biology Centre, The Queen's University of Belfast, Belfast BT9 7BL, UK

\begin{abstract}
The haloalkane dehalogenase (dhaA) gene from Rhodococcus rhodochrous NCIMB 13064 was cloned and sequenced. Its comparison with the previously studied dhIA gene from Xanthobacter autotrophicus GJ10 did not show homology. However, the amino acid sequences of the products of these genes showed approximately $\mathbf{3 0} \%$ identity and several of the catalytic amino acid residues were conserved in the NCIMB 13064 dehalogenase. A high level of dhaA expression was demonstrated in Escherichia coli cells and this gene was shown to encode a dehalogenase with the activity against chloroalkanes of chain length $\mathrm{C}_{3}-\mathrm{C}_{10}$. Also, some dehalogenase activity against 1,2dichloroethane encoded by the cloned dhaA gene was detected. The analysis of NCIMB 13064 derivatives lacking dehalogenase activity showed that the dhaA gene was located on the $100 \mathrm{kbp}$ PRTL1 plasmid. It was also found that reversible rearrangements of DNA in the dhaA region may be responsible for the control of expression of haloalkane dehalogenase in $R$. rhodochrous NCIMB 13064. A number of repeated and inverted sequences which may cause genetic instability at the locus were found in the haloalkane dehalogenase gene region.
\end{abstract}

Keywords: Rhodococcus rhodochrous, dhaA, Dha- derivatives, genome rearrangements

\section{INTRODUCTION}

Many haloalkanes persist in the environment to become major pollutants of the biosphere. Haloalkane dehalogenases have been found in Gram-negative (Keuning et al., 1985) and Gram-positive haloalkane-utilizing bacteria (Keuning et al., 1985; Yokota et al., 1987; Scholtz et al., 1987; Sallis et al., 1990). Haloalkane dehalogenases are unique enzymes which catalyse hydrolytic dehalogenation of corresponding hydrocarbons without participation of oxygen or coenzymes. The haloalkane dehalogenase (DhlA) from Xanthobacter autotrophicus GJ10 has been extensively studied and the sequence of the $d h l A$ gene determined (Janssen et al., 1988, 1989). However, very little is known about the genetic organization of haloalkane degradation in Grampositive bacteria.

Rhodococcus rhodochrous NCIMB 13064 can utilize a wide range of 1-haloalkanes as sole carbon and energy

The GSDB accession number for the sequence reported in this paper is L49435. source. Short-chain 1-chloroalkanes $\left(\mathrm{C}_{3}-\mathrm{C}_{8}\right)$ are metabolized by the initial action of a hydrolytic dehalogenase to produce the corresponding alcohol. However, growth on long-chain 1-chloroalkanes $\left(\mathrm{C}_{12}-\mathrm{C}_{18}\right)$ results only in a low level of dehalogenase activity. The attack on the long-chain 1-chloroalkanes is initiated by oxygenase action at the non-halogenated end to produce $\omega$ chlorofatty acids. These are then degraded by $\beta$ oxidation (Curragh et al., 1994). Two plasmids, pRTL1 $(100 \mathrm{kbp})$ and pRTL2 (80 kbp), have been found in strain NCIMB 13064; pRTL1 was shown to carry at least some genes for the dehalogenation of short-chain 1-chloroalkanes. No association was found between the utilization of 1-chloroalkanes with chain lengths of $\mathrm{C}_{12}-\mathrm{C}_{18}$ and the presence of pRTL1 in bacterial cells. This suggested that different genetic determinants are involved in the dehalogenation and utilization of shortand long-chain 1-chloroalkanes (Kulakova et al., 1995). Three separate genetic events independently led to the inability of NCIMB 13064 to dehalogenate short-chain 1-chloroalkanes: either the complete loss of pRTL1; or the integration of pRTL1 into the chromosome; or deletion of a $20 \mathrm{kbp}$ fragment from pRTL1. High- 
frequency transfer of the 1-chloroalkane degradation marker associated with pRTL1 was demonstrated in matings between different derivatives of $R$. rhodochrous NCIMB 13064 (Kulakova et al., 1995).

The haloalkane dehalogenase from $R$. rhodochrous NCIMB 13064 has been purified to homogeneity. It is monomeric and its molecular mass was determined to be $33 \mathrm{kDa}$ (Stafford, 1993). An analysis of the physicochemical characteristics of NCIMB 13064 dehalogenase suggested similarities with other haloalkane halidohydrolases. The first 17 residues of the $\mathrm{N}$-terminal amino acid sequence were identical to those reported for halidohydrolases with a similar substrate range isolated from Rhodococcus erythropolis (Sallis et al., 1990) and Arthrobacter sp. (Scholtz et al., 1987). However, no similarities were detected with the N-terminal amino acid sequence of the DhlA halidohydrolase isolated from Xanthobacter autotrophicus GJ10 (Keuning et al., 1985), which is the most extensively studied dehalogenase to date.

In this paper we report the cloning of a haloalkane dehalogenase gene from Rhodococcus rhodochrous NCIMB 13064, its sequencing and its expression in Escherichia coli. Analysis of some of NCIMB 13064 derivatives unable to utilize chloroalkanes is also presented.

\section{METHODS}

Bacterial strains and plasmids. E. coli DH $5 \alpha$ (Sambrook et al., 1989), cosmid vector pLAFR 5 and plasmid vector pUC129 (Keen et al., 1988) were used for the cloning experiments. $R$. rbodochrous NCIMB 13064 (sub-strain S14A3), which harbours two plasmids, pRTL1 and pRTL2, was employed in this study. Its derivatives unable to utilize short-chain chloroalkanes, S2 (pRTL2) and P200 (pRTL1 $\Delta 20 \mathrm{kbp}, \mathrm{pRTL} 2$ ), were described previously (Kulakova et al., 1995).

Media and growth conditions. Both $R$. rhodochrous and E. coli strains were grown in a rich (2YT) or minimal (M9) medium (Miller, 1972). When required, Difco agar $(1.8 \%$, $\mathrm{w} / \mathrm{v})$ was added to the medium. Ampicillin $\left(100 \mu \mathrm{g} \mathrm{m}^{-1}\right)$, tetracycline $\left(15 \mu \mathrm{g} \mathrm{ml}^{-1}\right)$, IPTG $\left(50 \mu \mathrm{g} \mathrm{ml}^{-1}\right)$ and X-Gal $\left(50 \mu \mathrm{g} \mathrm{m}^{-1}\right)$ were used for the detection of recombinant plasmids. Rich medium (2YT) without sodium chloride was used to screen for $E$. coli clones with chloroalkane dehalogenase activity. For the isolation of plasmid and total DNA from $R$. rhodochrous, strains were grown in YEP medium (Kulakova et al., 1995).

DNA techniques. Plasmid DNA from R. rhodochrous strains was isolated as described by Schreiner et al. (1991), and total DNA as described by Kulakova et al. (1995). Recombinant DNA work was done by using standard protocols as described by Sambrook et al. (1989). Restriction of both plasmid and total DNA was performed using enzymes obtained from Pharmacia for $12-20 \mathrm{~h}$, according to the manufacturer's instructions.

Agarose gel electrophoresis was carried out using 0.9-1\% $(\mathrm{w} / \mathrm{v})$ agarose in TAE buffer at $5-7 \mathrm{~V} \mathrm{~cm}^{-1}$. Low-meltingpoint agarose (Bio-Rad) was used for the recovery of DNA fragments. Fragments were then purified by phenol and phenol/chloroform extraction with subsequent ethanol precipitation.

DNA fragments were transferred to Z-probe membranes
(Bio-Rad) by Southern blotting, as described by Sambrook et al. (1989). The membranes were then treated according to the manufacturer's instructions. Hybridization probes were labelled with $\left[{ }^{32} \mathrm{P}\right] \mathrm{dCTP}$ using an oligolabelling kit (Pharmacia) and hybridization was carried out in $0.25 \mathrm{M} \mathrm{Na}_{2} \mathrm{HPO}_{4}, \mathrm{pH} 7 \cdot 2,7 \%(\mathrm{w} / \mathrm{v})$ SDS at the temperatures indicated in Results for between 6 and $12 \mathrm{~h}$.

Cloning of the dhaA gene from $R$. rhodochrous. Plasmid DNA (i.e. pRTL1 and pRTL2) isolated from R. rhodochrous NCIMB 13064 was partially digested with restriction endonuclease Sau3A. Fragments of 15-25 kbp were isolated and ligated with cosmid vector pLAFR 5 previously digested with $B a m \mathrm{HI}$ and ScaI. The resultant preparations were packaged into phage $\lambda$ heads using an in vitro packaging kit (Amersham) and transduced into $E$. coli $\mathrm{DH} 5 \alpha$ cells. Recombinant clones were tested for dehalogenase activity by release of chloride ions after growth to late exponential phase $\left(\right.$ at $30^{\circ} \mathrm{C} ; 10 \mathrm{ml}$ cultures) in chloride-free 2YT medium in the presence of 1 chlorobutane $(10 \mathrm{mM})$. Chloride ion release was measured using a Corning Chloride Analyser 926. Sub-cloning of $d h a A$ from $\mathrm{Dha}^{+}$cosmid clones was done using standard methods with plasmid vector pUC129 (Keen et al., 1988).

Measurement of dehalogenase activity. This was assayed in cell-free extracts of $R$. rhodochrous NCIMB 13064 after growth in minimal medium with 1-chlorobutane $(10 \mathrm{mM})$ as well as E. coli strains grown in 2YT medium. At the end of the exponential phase, cells were harvested, washed and resuspended in $50 \mathrm{mM}$ Tris $/ \mathrm{H}_{2} \mathrm{SO}_{4}(\mathrm{pH} \mathrm{8.0)}$. Cultures were disrupted by sonication at $0^{\circ} \mathrm{C}$ for $5 \mathrm{~min}$ (E. coli) and $12 \mathrm{~min}$ (R. rhodochrous) using an MSE Soniprep 150 set at maximum power (peak-to-peak amplitude $12 \mu \mathrm{m}$ ). Preparations were cleared by centrifugation at $35000 \mathrm{~g}$ for $1 \mathrm{~h}$ at $4^{\circ} \mathrm{C}$. Assay substrate was added to a concentration of $10 \mathrm{mM}$ and chloride ion release was measured using a Corning Chloride Analyser 926. Corrections were made for abiotic chloride release. Protein concentrations were determined by the method of Bradford (1976), using bovine serum albumin as standard.

DNA sequencing. Recombinant pUC129 plasmids with insertions containing the $d h a A$ gene were used as templates for the Taq Dye-Deoxy Terminator Cycle Sequencing Kit (Applied Biosystems). DNA sequences were read on an automatic DNA sequencer (Applied Biosystems, model 373A). The DNA sequence of the dehalogenase region (plasmid pUTL11X) was determined using sub-clones of this plasmid and additional primers. Primer synthesis was performed by $\mathrm{Dr}$ C. Stevenson (School of Biology and Biochemistry, The Queen's University of Belfast). The nucleotide sequences of both strands were determined. Computer analysis of the sequences was performed using the DNASIS (Hitachi) software package. Alignment of the protein sequences and analysis of the phylogenetic relationship between corresponding enzymes were performed using the Higgins-Sharp algorithm (Higgins $\&$ Sharp, 1988). Searches for nucleotide and amino acid sequence similarities were done by using the FASTA program (Pearson \& Lipman, 1988) in the EMBL database.

\section{RESULTS}

\section{Cloning of haloalkane dehalogenase gene dhaA}

A gene bank of $R$. rhodochrous NCIMB 13064 plasmid DNA was constructed as described in Methods. Plasmid DNA preparations were used, because our previous results suggested that dehalogenation of short-chain chloroalkanes was associated with one of the two plasmids present in this strain (Kulakova et al., 1995). 
Table 1. Dehalogenation of chloroalkanes by $R$. rhodochrous NCIMB 13064 and $E$. coli recombinant strains

\begin{tabular}{|c|c|c|c|c|c|c|c|c|}
\hline \multirow[t]{2}{*}{ Organism (plasmid) } & \multicolumn{8}{|c|}{ Specific activity $\left(\mathrm{nmol} \mathrm{min}^{-1} \mathrm{mg}^{-1}\right)^{*}$} \\
\hline & $\mathrm{ClC}_{3}$ & $\mathrm{ClC}_{4}$ & $\mathrm{ClC}_{6}$ & $\mathrm{ClC}_{8}$ & $\mathrm{ClC}_{9}$ & $\mathrm{ClC}_{10}$ & $\mathrm{ClC}_{16}$ & DCE \\
\hline R. rbodochrous NCIMB 13064(pRTL1, pRTL2) & 40 & 80 & 72 & 58 & 16 & 20 & 5 & $<1$ \\
\hline \multicolumn{9}{|l|}{ E. coli } \\
\hline $\mathrm{DH} 5 \alpha(\mathrm{pLTL} 1 \mathrm{k})$ & 7 & 32 & 28 & 24 & 11 & 10 & $<1$ & 3 \\
\hline $\mathrm{DH} 5 \alpha(\mathrm{pUTL} 11)$ & ND & 120 & 112 & 60 & 43 & 32 & $<1$ & 10 \\
\hline DH5 $\alpha($ pUTL11X $)$ & 38 & 115 & ND & 68 & 40 & 28 & $<1$ & 10 \\
\hline DH $5 \alpha($ pUTL112) & $<1$ & $<1$ & $<1$ & $<1$ & ND & $<1$ & $<1$ & ND \\
\hline
\end{tabular}

* Dehalogenation was measured as chloride ion released when assay substrate was added to a concentration of $10 \mathrm{mM}$ to cell-free extracts. $\mathrm{ClC}_{3}$, 1-chloropropane; $\mathrm{ClC}_{4}$, 1-chlorobutane; $\mathrm{ClC}_{6}$, 1-chlorohexane; $\mathrm{ClC}_{8}$, 1-chlorooctane; $\mathrm{ClC}_{9}$, 1-chlorononane; $\mathrm{ClC}_{10}$, 1chlorodecane; $\mathrm{ClC}_{16}$, 1-chlorohexadecane; DCE, 1,2-dichloroethane. The results are the means of two experiments. ND, Not determined.

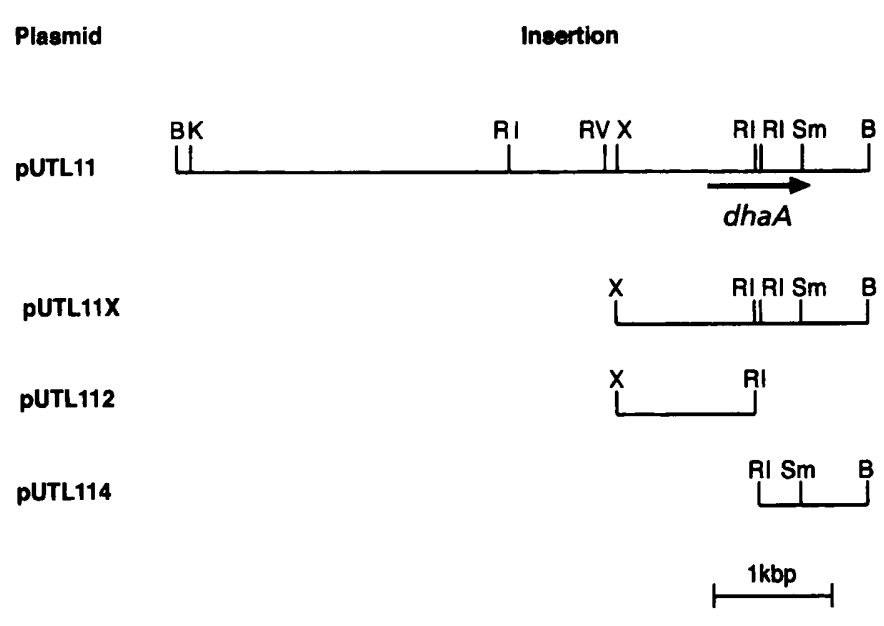

Dehalogenase activity

Plasmid
pUTL114

Most of the recombinant clones tested (23 out of 25 ) had plasmid inserts with an average size of $23 \pm 5 \mathrm{kbp}$. To facilitate the screening procedure the dehalogenase activity of clones was measured after growth in chloridefree $2 \mathrm{YT}$ medium in the presence of 1-chlorobutane as described in Methods, and four clones out of 115 tested showed an increased chloride ion release. Restriction analysis of the corresponding recombinant plasmids (pLTL1k, pLTL52, pLTL23 and pLTL4) indicated a common region in the cloned DNA. Plasmid pLTL1k (insertion of $18.4 \mathrm{kbp}$ ) was chosen for further analysis. The $5.8 \mathrm{kbp} \mathrm{BamHI}$ fragment containing the putative haloalkane dehalogenase gene $(d h a A)$ was sub-cloned from this plasmid into the pUC129 vector, and the resulting plasmid was designated pUTL11. When transformed with this plasmid, E. coli $\mathrm{DH} 5 \alpha$ expressed higher dehalogenase activities than detected in the original $\mathrm{Dha}^{+}$clones (Table 1). Restriction mapping and further sub-cloning resulted in the localization of the $d h a A$ gene within the $2 \mathrm{kbp}$ DNA fragment of plasmid pUTL11X (Fig. 1).

\section{Expression of haloalkane dehalogenase DhaA in E. coli}

The dehalogenase activity and substrate range were measured for the key clones using resting $E$. coli cells and cell-free extracts incubated with the appropriate substrate (Table 1). All of the $\mathrm{Dha}^{+}$E. coli clones expressed dehalogenase activity against short-chain $\left(\mathrm{C}_{3}-\mathrm{C}_{8}\right)$ chloroalkanes, as well as 1-chlorononane and 1chlorodecane. Dehalogenase activities in the pUC129based clones were significantly higher (probably due to a copy number effect) than in the pLAFR5-based ones. In fact, they were even higher than the activities expressed by the original $R$. rhodochrous strain (Table 1). The effective expression of haloalkane dehalogenase in E. coli was previously shown for the gene cloned from $X$. autotrophicus GJ10 (Janssen et al., 1989), but in the case of Rhodococcus it was less expected because of the evolutionary distance between these species. Surprisingly, a low level of dehalogenase activity against 1,2-dichloroethane was detected in clones containing 
CGGGCAAGGTACTTGTTCGGCTGCCTGATCGGAAATTTCAGCGTAGAACTCAGCCCGTT GAGTGATGTCGTTAGAACAGAACTCTTGCGCATCTTCGAGCAATGGGTGAAGCCATTCCA AAAATGTATAATT GAAGGGCAGGAAACGGGGTCGATCCGCCGCGATTTGGCTCCAGATCT GTTGGCCGACTTCTTGATTGCCTCCTGGCAAGGTGCCATCCTGCGGATGAAGATCGAACG CAACCGCGAGCCATTAGATCAGTTCCTGACTGTAGTGTTCGAGGCGCTCCTGCCATCCAC AGAGAACATTTCCAACGAATCCTGAACGAGTTCATCCCACGTCCGCAAAGCTAGGCCGTT GGCAGACGTAGGATGCTGCATGAGGCAGCGAAATGAGACCGAAGGTCCAGAATCAAGCGC CCGCGGAACTCGTTAGGAACGCTTACATATAGGCGATACTAGATTTATTCCAGCCAGGGT AGTAATCTGCATCACAAGCAGGTGGTGGTATGGCGTCCGCCGCCTCGCTTGCACAGTTCC CAGTTCTGCGAACTCTGTTCGGCTCGCGATGTCCCGTCTCGGTCCATCAGCCTCGGACAA AAGTTTACTTCGTCTGNAAREAC CETCATCTCGGACGGATCGAGATGGCTCCGGCGTGG

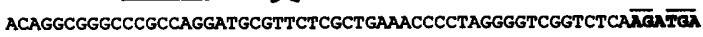
$\overrightarrow{C C}$ GOTCACCTTAAGTTGAAGGAAAATCGAAATGTCAGAAATCGGTACAGGCTTCCCCTT
M S E I G T G F P F $M$ S S $E$ I $I$ G

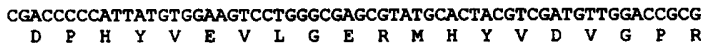
GGATGGCACGCCTGTGCTGTTCCTGCACGGTAACCCGACCTCGTCCTACCTGTGGCGCAA

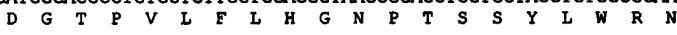
CATCATCCCGCATGTAGCACCGAGTCATCGGTGCATTGCTCCAGACCTGATCGGGATGGG

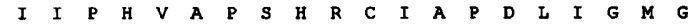
AAAATCGGACAAACCAGACCTCGATTATTTCTTCGACGACCACGTCCGCTACCTCGATGC $\begin{array}{llllllllllllllllllll}K & S & D & K & P & D & L & D & Y & F & F & D & D & H & V & R & Y & \text { L } & D & A\end{array}$ CTTCATCGAAGCCTTGGGTTTGGAAGAGGTCGTCCTGGTCATCCACGACTGGGGCTCAGC $\begin{array}{lllllllllllllllllllll} & \text { F } & \text { I } & \text { E } & \text { A } & \text { L } & G & \text { L } & \text { E } & \text { E } & \text { V } & \text { V } & \text { I } & \text { V } & \text { I } & \text { H } & \text { D } & \text { W } & G & \text { S } & \text { A }\end{array}$ TCTCGGATTCCACTGGGCCAAGCGCAATCCGGAACGGGTCAAAGGTATTGCATGTATGGA

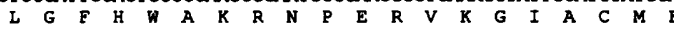
ATTCATCCGGCCTATCCCGACGTGGGACGAATGGCCGGAATTCGCCCGTGAGACCTTCCA $\begin{array}{lllllllllllllllllllll} & F & I & R & P & I & P & T & W & D & E & W & P & E & F & A & R & E & T & F & 0\end{array}$ GGCCTTCCGGACCGCCGACGTCGGCCGAGAGTTGATCATCGATCAGAACGCTTTCATCGA

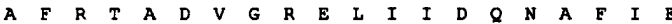
GGGTGCGCTCCCGAAATGCGTCGTCCGTCCGCTTACGGAGGTCGAGATGGACCACTATCG $\begin{array}{llllllllllllllllllll}G & A & \text { L } & \text { P } & \text { K } & \text { C } & \text { V } & \text { V } & \text { R } & \text { P } & \text { L } & \text { T } & \text { E } & \text { V } & \text { E } & \text { M } & \text { D } & \text { H } & \text { Y } & R\end{array}$ CGAGCCCTTCCTCAAGCCTGTTGACCGAGAGCCACTGTGGCGATTCCCCAACGAGCTGCC E P F I K P D R E P L W R P N E I P CATCGCCGGTGAGCCCGCGAACATCGTCGCGCTCGTCGAGGCATACATGAACTGGCTGCA

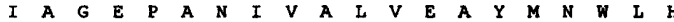
CCAGTCACCTGTCCCGAATTGTTGTTCTGGGGCACACCCGGCGTACTGATCCCCCCGGC

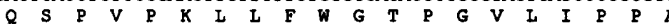
CGAAGCCGCGAGACTTGCCGAAAGCCTCCCCAACTGCAAGACAGTGGACATCGGCCCGGG

$\begin{array}{llllllllllllllllllll} & E & A & A & R & L & A & E & S & L & P & N & C & K & T & V & D & I & G & P\end{array}$ ATTGCACTACCTCCAGGAAGACAACCCGGACCTTATCGGCAGTGAGATCGCGCGCTGGCT $\begin{array}{llllllllllllllllllll}\text { L } & \text { H } & \text { Y } & \text { L } & \text { Q } & \text { E } & \text { D } & \text { N } & \text { P } & \text { D } & \text { L } & \text { I } & G & \text { S } & \text { E } & \text { I } & \text { A } & \text { R } & \text { W } & \text { I }\end{array}$ CCCCGCACTCTAGGTTCACGTCACGGTCCGATGTCCAGGCCGACTTCGGCGTCGAAGCCG AGGTCGGAATGCTGACCGGTCT CACCAATGCCAAACCTGACACCCCAACCGCAGCCGTCG ACGAACCCCGCGACCAGCAGTAGTGGAATACGGGAGAACGAAGCATCCAATGAAACATTG TGCTGCTGCTTGTATCCCAGCTCTTCAGCCGAGTGGCCACTTGGGAGTTTGGCCACCCGC ATTGGTTTGTCGCCAAGCGGACTTCGGCCACCTTTTCCGTCACTTACGTGCTGTCCGTCG TGGCAGTACAAGCGCAACAAGGCTGCTCGGCAGCCTTTGTCCCGATAGTAAAAAATTCAC ACCCTCTTGTGGGTCGTGATGCCTAACCAAGTTCGGACGGTGTGACGTCCGACATTCGAG AAGGAGATAAATGATGAAGACTCAGGCAGCCATCTTGTGGGAGCGAGGGGCCCGTGGAG CGTCGAGGAGATCGATCT

Fig. 2. Nucleotide sequence of the haloalkane dehalogenase (dhaA) gene region. The nucleotide sequence was obtained from pUTL11X (Fig. 1). The deduced amino acid sequence of haloalkane dehalogenase is shown below the nucleotide sequence. A putative ribosome-binding site (nt 740-745) is designated by underlining; a rho-independent terminator (nt 1660-1687) and palindrome sequence in the region upstream of dhaA (nt 611-638) are shown by underlining with arrows. An inverted repeat (nt 617-730) is shown in bold and palindromic sequences inside it indicated by overlining with arrows.

plasmids pUTL11 and its shortened derivative pUTL11X (Table 1, and Fig. 1).

\section{Nucleotide sequence analysis of the haloalkane dehalogenase gene region}

The nucleotide sequence of the $2118 \mathrm{bp}$ fragment in plasmid pUTL11X encoding the haloalkane dehalogenase gene was determined (Fig. 2). Only one ORF, which could encode a protein of approximately $30 \mathrm{kDa}$, was found. Correspondence of this ORF to the $d h a A$ gene was confirmed on the basis of the known $\mathrm{N}$ terminal sequence (first 19 amino acids) of the NCIMB 13064 haloalkane dehalogenase (Stafford, 1993). The ORF (nt 752-1633) is preceded by a possible ribosomebinding site (Shine \& Dalgarno, 1974) and it encodes a protein of 292 amino acids with a calculated molecular mass of $33244 \mathrm{Da}$, corresponding closely with that determined for the purified haloalkane dehalogenase (Stafford, 1993).

Computer analysis of the $d h a A$ region revealed the presence of direct (DR) and inverted (IR) repeats (Fig. 2). The most interesting structural feature was found in the $150 \mathrm{bp}$ region upstream of the $d h a A$ gene, where two overlapping IRs of 16 and $13 \mathrm{bp}$ are present. The IR AGATGACCGGTCATCT (nt 617-730) in its turn has a complex structure in that $8 \mathrm{bp}$ inverted sequences (AGATGACC) are present within it. Also the upstream part of the bigger repeat (nt 617) partially overlaps with, and the downstream part (nt 715) completely overlaps with, the DR sequence AGATGACCGGTCA (nt 617 and 715, Fig. 2). These IRs may form a stable stem-loop structures [the free energy of the nt $617-730$ region, calculated using RNA energy values, was $\Delta G=$ $-33.3 \mathrm{kcal} \mathrm{mol}^{-1}\left(-139.3 \mathrm{~kJ} \mathrm{~mol}^{-1}\right)$ and that for the nt $611-638$ repeat was $\Delta G=-26.4 \mathrm{kcal} \mathrm{mol}^{-1}$ $\left.\left(-110 \cdot 5 \mathrm{~kJ} \mathrm{~mol}^{-1}\right)\right]$.

A sequence with a structure typical of $r h o$-independent terminators (Carafa et al., 1990) with a predicted free energy $(\Delta G)$ of $-26.2 \mathrm{kcal} \mathrm{mol}^{-1}\left(-109.6 \mathrm{~kJ} \mathrm{~mol}^{-1}\right)$ was identified 26 nucleotides downstream from the termination codon (Fig. 2).

The nucleotide sequence of the $d h a A$ gene has only $59 \%$ similarity in a 301 bp overlap with the $d b l A$ gene from $X$. autotrophicus GJ10 (Janssen et al., 1989). The deduced amino acid sequence of the $d h a A$ gene exhibited approximately $30 \%$ identity with the $d h l A$ product (Fig. $3)$. Significant similarity was also found with the amino acid sequence of haloacetate dehalogenase (DehH1) from Moraxella sp. (Kawasaki et al., 1992) (Fig. 3).

\section{Analysis of Dha' mutant strains}

It was previously shown that short-chain haloalkane degradation in $R$. rhodochrous NCIMB 13064 was likely to be controlled by the pRTL1 plasmid. However, we had no proof that the $d h a A$ gene was located on this plasmid. In order to locate the haloalkane dehalogenase, a $2 \mathrm{kbp} X$ bal-BamHI fragment of plasmid pUTL11X, which included the $d h a A$ gene with adjacent regions, was purified and used as a probe in Southern hybridization experiments with plasmid and total DNA isolated from NCIMB 13064. Under conditions of high stringency (hybridization at $65^{\circ} \mathrm{C}$ for $6 \mathrm{~h}$ ) hybridization signals were detected with plasmid and total DNA preparations from the parental NCIMB 13064 strain. However, there was no hybridization with DNA from the $\mathrm{Dha}^{-} \mathrm{S} 2$ derivative, which lacks pRTL1. These results clearly indicate that the haloalkane dehalogenase gene is located on the pRTL1 plasmid. 


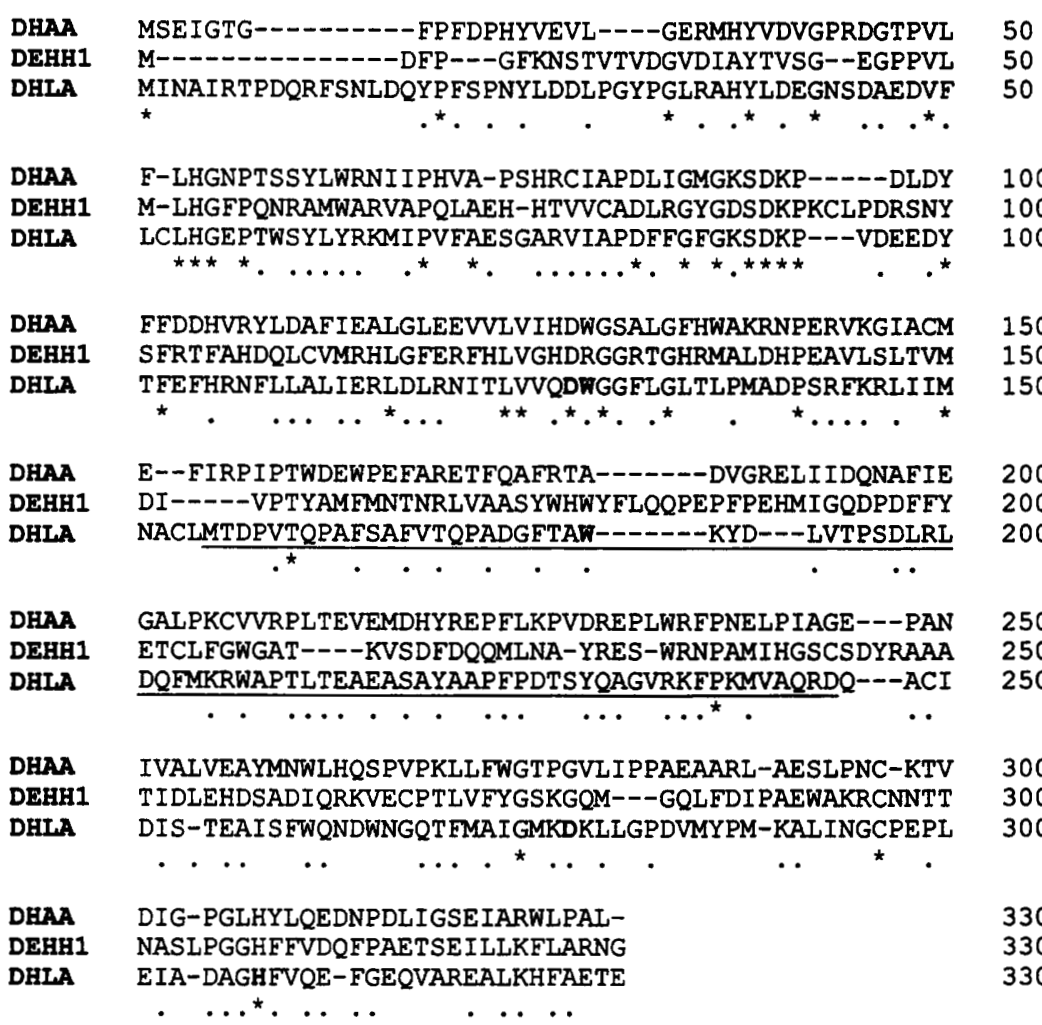
proteins are indicated by asterisks and those identical in two of the proteins by dots.
Previously we reported that the $\mathrm{P} 200 \mathrm{Dha}^{-}$derivative of NCIMB 13064, which had lost a $20 \mathrm{kbp}$ fragment of pRTL1, could revert to the original $\mathrm{Dha}^{+}$phenotype (revertants were detected in cell populations at a frequency of approximately $10^{-7}$ ) with the restoration of pRTL1 (Kulakova et al., 1995). However, no hybridization of DNA from this strain was detected with the $d h a A$ probe under conditions of high stringency. In this study another spontaneous $\mathrm{Dha}^{-}$mutant (P400) was isolated which had lost both pRTL1 and pRTL2. Surprisingly, this strain was also able to revert to the $\mathrm{Dha}^{+}$phenotype at a frequency of about $10^{-7}-10^{-8}$, with restoration of the original plasmids. It was therefore of interest to determine the state of the $d h a A$ locus in these derivatives. To do this, total DNA preparations from strains $\mathrm{P} 200$ and P400 were hybridized with the EcoRI-BamHI (nt 1178-2118) fragment of pUTL11X, using varying conditions of stringency (i.e. temperatures of hybridization from $40^{\circ} \mathrm{C}$ to $65^{\circ} \mathrm{C}$ with $5^{\circ} \mathrm{C}$ intervals) and times of hybridization (from 4 to $18 \mathrm{~h}$ ). The results presented in Fig. 4 were obtained when hybridization with this probe was carried out at $50^{\circ} \mathrm{C}$ for $6 \mathrm{~h}$. This probe gave one band when hybridized with total DNA BamHI digests of $\mathrm{Dha}^{+}$ NCIMB 13064 and P210 (a Dha ${ }^{+}$revertant of P200), but several bands of hybridization were detected with Bam HI digests of $\mathrm{Dha}^{-}$strains $\mathrm{P} 200$ and P400. There was no difference in the hybridization patterns of strains P200 and P400. Four intense signals were in the region of fragments with a lower molecular mass than that of the parent NCIMB 13064. Similar results were obtained when the XbaI-BamHI fragment of pUTL11X was used as a probe (data not shown). However, when hybridization was carried out at temperatures above $60^{\circ} \mathrm{C}$ no signal was detected with strains P200 and P400, and at temperatures below $45^{\circ} \mathrm{C}$ non-specific hybridization was observed. Hybridization of the same NCIMB 13064, P200 and P400 strains with a $1.5 \mathrm{kbp}$ DNA fragment cloned from a different region of the NCIMB 13064 genome resulted in signals of approximately equal intensity with all DNAs at $50^{\circ} \mathrm{C}$ and $60^{\circ} \mathrm{C}$ (results not shown). The results obtained indicated that rearrangements of genetic material may have occurred in the NCIMB 13064 strain in the region of the dhaA locus, and these were probably responsible for the loss of expression of this gene.

\section{DISCUSSION}

There are a number of reports describing microorganisms with the ability to utilize chlorinated hydrocarbons. The haloalkane dehalogenase determinants in Arthrobacter sp. HA1 (Scholtz et al., 1987) and Rhodococcus erythropolis Y2 (Sallis et al., 1990) might be similar to that described in this paper according to the $\mathrm{N}$-terminal amino acid sequence similarities of the enzymes. It was shown that $R$. erythropolis Y2 harboured a plasmid, although it was not shown to be associated with dehalogenase activity (Sallis et al., 1990). The only haloalkane dehalogenase gene $(d h l A)$ which has been cloned and sequenced to date is from $X$. autotrophicus GJ10 (Janssen et al., 1989). This gene was found to be located on the plasmid pXAU1 (Tardif et al., 1991). The X-ray structure of the GJ10 haloalkane 


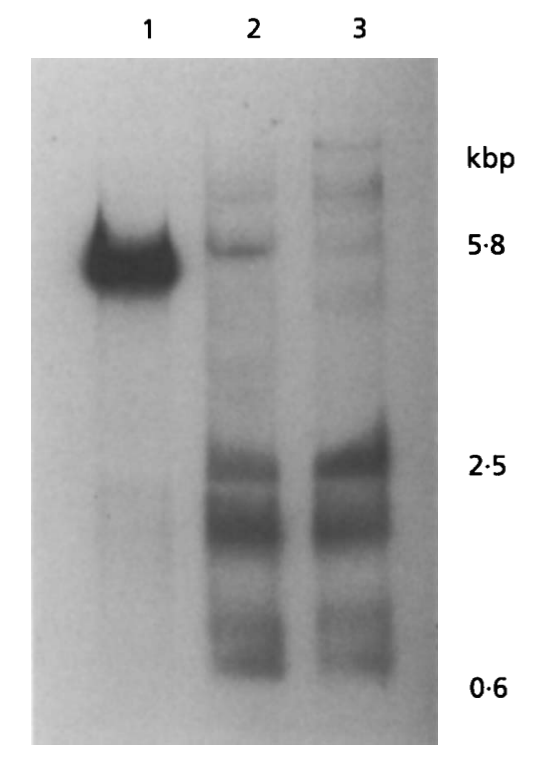

Fig. 4. Hybridization analysis of the dhaA gene region in $R$. rhodochrous NCIMB 13064 and its Dha- derivatives. P200 (which has a $20 \mathrm{kbp}$ deletion in plasmid pRTL1: Kulakova et al., 1995) and P400 (which has lost plasmids PRTL1 and pRTL2). Total DNA from NCIMB 13064 (lane 1), P200 (lane 2) and P400 (lane 3) was restricted with $\mathrm{BamHI}$, separated in $0.9 \%$ agarose gel and transferred onto Z-probe membrane. Hybridization was performed with the ${ }^{32} \mathrm{P}$-labelled EcoRI-BamHI fragment isolated from pUTL11X (nt 1178-2118; Fig. 2) at $50^{\circ} \mathrm{C}$ for $6 \mathrm{~h}$.

dehalogenase has been determined (Franken et al., 1991; Verschueren et al., 1993). The enzyme has two domains, and the catalytic residues are situated in the cavity between them, which is reported to be the substratebinding site (Franken et al., 1991).

The nucleotide sequences of the $d h l A$ and $d h a A$ genes do not exhibit significant homology. However, comparison of the amino acid sequences of the corresponding enzymes and of Moraxella sp. haloacetate dehalogenase (Kawasaki et al., 1992) revealed some important features (Fig. 3). A number of amino acid residues which were shown to play a catalytic role in DhlA are conserved in the NCIMB 13064 dehalogenase. These are: Asp124, which was suggested to be a nucleolitic residue (Pries et al., 1994); and Trp125 (Verschueren et al., 1993; Pries, 1995) and His289, which were shown to be essential for the hydrolysis of the alkyl-enzyme intermediate (Pries et al., 1995). According to the DNA sequence analysis of dhaA presented here, catalytic Trp175 and Asp260 (charge relay) (Verschueren et al., 1993; Pries, 1995) were not conserved in the $R$. rhodochrous NCIMB 13064 haloalkane dehalogenase. Asp124 and His289 residues were also conserved in the DehH1 haloacetate dehalogenase (Kawasaki et al., 1992). In the region which corresponds to the Cap domain of the DhlA dehalogenase, the similarities are more pronounced in the C-terminal part. The results of the computer analysis of the all three dehalogenases indicated closer evolutionary relations between the two haloalkane dehalogenases than with the haloacetate dehalogenase (matching percentages are $8.5 \%$ and $4.4 \%$, respectively).

Other investigators have demonstrated that dehalogenase genes may be located on plasmids (Tardif et al., 1991) or on transposable elements (Slater et al., 1985; Thomas et al., 1992a, b). In this report we demonstrate that the $d b a A$ gene of $R$. rbodochrous NCIMB 13064 is located on the $100 \mathrm{kbp}$ plasmid pRTL1. This plasmid was previously shown to be transmissible in matings between $R$. rhodochrous strains (Kulakova et al., 1995). Only dehalogenation of haloalkanes with shorter chains $\left(\mathrm{C}_{3}-\mathrm{C}_{10}\right)$ is encoded by the $d h a A$ gene and the pRTL1 plasmid. A different dehalogenation system(s) is probably involved in the utilization of haloalkanes with longer chains by NCIMB 13064.

In this work we investigated mutations associated with the $d b a A$ locus in two revertible $\mathrm{Dha}^{-}$derivatives. Unexpectedly, we found that in $\mathrm{Dha}^{-}$strains P200 and P400 hybridization of $d h a A$ probe evidently occurred with several regions of the genome. These results suggest that genomic rearrangements in NCIMB 13064 may occur in the region of the haloalkane dehalogenase locus. It is worth noting that genomic rearrangements are well documented in the genus Streptomyces, which represents an extensively studied group of Grampositive micro-organisms. Genetic instability of these micro-organisms is usually associated with rearrangements of their genomes (Birch et al., 1989; Flett \& Cullum, 1987; Schneider et al., 1993). It is also well established that perfect and imperfect direct repeats (McCorkle \& Altman, 1982; Lopez et al., 1984) as well as palindromic sequences (DasGupta et al., 1987; Peeters et al., 1988) can increase the frequency of genomic rearrangements in different micro-organisms. Inverted and direct repeats present in the dhaA gene region may be responsible for rearrangements in haloalkane dehalogenase. However, the role of genomic rearrangements in the $d h a A$ region of $R$. rhodochrous remains to be elucidated.

\section{ACKNOWLEDGEMENTS}

This project was supported by The Queen's University Environmental Science and Technology Research Centre. We are especially grateful to Dr Clark Stevenson for the synthesis of sequencing primers.

\section{REFERENCES}

Birch, A., Hauusler, A., Vogtli, M., Krek, W. \& Hutter, R. (1989). Extremely large chromosomal deletions are intimately involved in genetic instability and genomic rearrangements in Streptomyces glaucescens. Mol Gen Genet 217, 447-458.

Bradford, M. M. (1976). A rapid and sensitive detection method for the quantitation of microgram quantities of protein utilising the principle of protein-dye binding. Anal Biochem 72, 248-254.

Carafa, Y. A., Brody, E. \& Thermes, C. (1990). Prediction of rhoindependent Escherichia coli transcription terminators. $J \mathrm{Mol}$ Biol 216, 835-858. 
Curragh, H., Flynn, O., Larkin, M. J., Stafford, T. M., Hamilton, J. T. G. \& Harper, D. B. (1994). Haloalkane degradation and assimilation by Rhodococcus rhodochrous NCIMB 13064. Microbiology 140, 1433-1442.

DasGupta, U., Weston, H. K. \& Berg, D. E. (1987). Local DNA sequence control of deletion formation in Escherichia coli plasmid pBR322. Genetics 115, 41-49.

Flett, F. \& Cullum, J. (1987). DNA deletions in spontaneous chloramphenicol-sensitive mutants of Streptomyces coelicolor A3(2) and Streptomyces lividans 66. Mol Gen Genet 207, 499-502.

Franken, S. M., Rozenboom, H. J., Kalk, K. H. \& Dijkstra, B. W. (1991). Crystal structure of haloalkane dehalogenase: an enzyme to deoxify halogenated alkanes. EMBO J 10, 1297-1302.

Higgins, D. G. \& Sharp, P. M. (1988). CluSTAL: a package for performing multiple sequence alignments on a microcomputer. Gene 73, 237-244.

Janssen, D. B., Gerritse, J., Brakman, J., Kalk, C., Jager, D. \& Witholt, B. (1988). Purification and characterisation of a bacterial dehalogenase with activity towards halogenated alkanes, alcohols and ethers. Eur J Biochem 171, 67-72.

Janssen, D. B., Pries, P., Vander Ploeg, J., Kazemier, B. \& Terpstra, P. (1989). Cloning of 1,2-dichloroethane degradation genes of Xanthobacter autotrophicus GJ10 and expression and sequencing of the dhlA gene. J Bacteriol 171, 6791-6799.

Kawasaki, H., Tsuda, K., Matsushita, I. \& Tonomura, K. (1992). Lack of homology between two haloacetate dehalogenase genes encoded on a plasmid from Moraxella sp. strain B. J Gen Microbiol 138, 1317-1323.

Keen, N. T., Tamaki, S., Kobayashi, D. \& Trollinger, D. (1988). Improved broad-host-range plasmids for DNA cloning in Gramnegative bacteria. Gene 70, 191-197.

Keuning, S., Janssen, D. B. \& Witholt, B. (1985). Purification and characterisation of a hydrolytic haloalkane dehalogenase from Xanthobacter autotrophicus GJ10. J Bacteriol 163, 635-639.

Kulakova, A. N., Stafford, T. M., Larkin, M. J. \& Kulakov, L. A. (1995). Plasmid pRTL1 controlling 1-chloroalkane degradation by Rhodococcus rhodochrous NCIMB 13064. Plasmid 33, 208-217.

Lopez, P., Espinosa, M., Greeberg, B. \& Lacks, S. A. (1984). Generation of deletions on pneumococcal $\mathrm{mal}$ genes cloned in Bacillus subtilis. Proc Natl Acad Sci USA 81, 5189-5193.

McCorkle, G. \& Altman, S. (1982). Large deletion mutants of Escherichia coli tRNA ${ }^{\text {tyr }}$. J Mol Biol 155, 83-103.

Miller, J. H. (1972). Experiments in Molecular Genetics. Cold Spring Harbor, NY: Cold Spring Harbor Laboratory.

Pearson, W. R. \& Lipman, D. J. (1988). Improved tools for biological sequence comparison. Proc Natl Acad Sci USA 85, 2444-2448.

Peeters, B. P. H., de Boer, J. H., Bron, S. \& Venema, G. (1988). Structural plasmid instability in Bacillus subtilis: effect of direct and inverted repeats. Mol Gen Genet 212, 450-458.

Pries, F. (1995). Protein engineering of haloalkane dehalogenase. PhD thesis, Rijksuniversiteit Groningen.

Pries, F., Kingma, J., Pentenga, M., Van Pouderoyen, G., Jeronimus-Straingh, C. M., Bruins, A. P. \& Janssen, D. B. (1994). Site directed mutagenesis and oxygen isotope incorporation studies of the nucleophilic asparate of haloalkane dehalogenase. Biochemistry 33, 1242-1247.

Pries, F., Kingma, J., Krooshof, G. H., Jeronimus-Stratingh, C. M., Bruins, A. P. \& Janssen, D. B. (1995). Histidine289 is essential for hydrolysis of the alkyl-enzyme intermediate of haloalkane dehalogenase. J Biol Chem 270, 10405-10411.

Sallis, P. J., Armfield, S. J., Bull, A. F. \& Hardman, D. H. (1990). Isolation and characterisation of halidohydrolase from Rhodococcus erythropolis Y2. J Gen Microbiol 136, 115-120.

Sambrook, J., Fritsch, E. F. \& Maniatis, T. (1989). Molecular Cloning: a Laboratory Manual, 2nd edn. Cold Spring Harbor, NY: Cold Spring Harbor Laboratory.

Schneider, D., Aigle, B., Leblond, P., Simonet, J.-M. \& Decaris, B. (1993). Analysis of genome instability in Streptomyces ambofaciens. J Gen Microbiol 139, 2559-2567.

Scholtz, R., Leisinger, T., Suter, F. \& Cook, A. M. (1987). Characterisation of 1-chlorohexane halidohydrolase, a dehalogenase of a wide substrate range from Arthrobacter sp. J Bacteriol 169, 5016-5021.

Schreiner, A., Fochs, K., Lottspeich, F., Poth, H. \& Lingens, F. (1991). Degradation of 2-methylaniline in Rhodococcus rhodochrous: cloning and expression of two clustered catechol 2,3-dioxygenase genes from strain CTM. J Gen Microbiol 137, 2041-2048.

Shine, J. \& Dalgarno, L. (1974). The 3'-terminal sequence of Escherichia coli $16 \mathrm{~S}$ ribosomal RNA: complementarity to nonsense triplets and ribosomal binding sites. Proc Natl Acad Sci USA 71, 1342-1346.

Slater, J. H., Weightman, A. J. \& Hall, B. G. (1985). Dehalogenase genes of Pseudomonas putida PP3 on chromosomally located transposable elements. Mol Biol Evol 2, 557-567.

Stafford, T. M. (1993). Haloalkane degradation by Rhodococcus rhodochrous NCIMB 13064. PhD thesis, The Queen's University of Belfast.

Tardif, G., Greer, C. W., Labbe, D. \& Lan, P. C. K. (1991). Involvement of a large plasmid in the degradation of 1,2dichloroethane by Xanthobacter autotrophicus. Appl Environ Microbiol 57, 1853-1857.

Thomas, A. W., Slater, J. H. \& Weightman, A. J. (1992a). The dehalogenase gene dehI from Pseudomonas putida PP3 is carried on an unusual mobile genetic element designated DEH.J Bacteriol 174, 1932-1940.

Thomas, A. W., Topping, A. W., Slater, J. H. \& Weightman, A. J. (1992b). Localisation and functional analysis of structural and regulatory dehalogenase genes carried on $D E H$ from Pseudomonas putida PP3. J Bacteriol 174, 1941-1947.

Verschueren, K. H. G., Franken, S. M., Rozenboom, H. J., Kalk, K. H. \& Dijkstra, B. W. (1993). Refined X-ray structures of haloalkane dehalogenase at $\mathrm{pH} \mathrm{6.2} \mathrm{and} \mathrm{pH} 8.2$ and implications for the reaction mechanism. J Mol Biol 232, 856-872.

Yokota, T., Omori, T. \& Kodama, T. (1987). Purification and properties of haloalkane dehalogenase from Corynebacterium sp. strain m15-3. J Bacteriol 169, 4049-4054.

Received 25 April 1996; revised 29 August 1996; accepted 6 September 1996. 